\title{
Clinical and bronchoscopic diagnosis of suspected pneumonia related to AIDS
}

\author{
A L POZNIAK, $\mathrm{K}$ T TUNG, C R SWINBURN, S TOVEY, S J G SEMPLE, \\ $\mathrm{N}$ MCI JOHNSON
}

\begin{abstract}
In a series of 25 patients with suspected pneumonia related to the acquired immune deficiency syndrome (AIDS) the first 12 underwent routine fibreoptic bronchoscopy and bronchoalveolar lavage with or without transbronchial biopsy before treatment. Eight were found to have Pneumocystis carinii pneumonia and had typical clinical presentations with a prolonged history of symptoms, including a dry cough, and bilateral diffuse alveolar or interstitial shadowing in chest radiographs.

Among the subsequent 13 cases, 11 had similar clinical presentations and were treated with high doses of intravenous cotrimoxazole without bronchoscopy first. Bronchoscopy was performed in those who deteriorated at any stage or failed to improve by the fifth day of treatment. Nine patients recovered and were discharged. In two patients who died $\mathbf{P}$ carinii pneumonia was confirmed in one but no diagnosis was made in the other. The early and late survival in both groups of patients was similar.

In patients at high risk for AIDS who have clinical features suggestive of $\mathbf{P}$ carinii pneumonia starting treatment with intravenous co-trimoxazole is justified. The few patients who
\end{abstract}

Department of Medicine, Middlesex Hospital, London WIN 8AA

A L POZNIAK, MRCP, medical registrar

K T TUNG, MA, MRCP, medical registrar

C R SWINBURN, MD, MRCP, medical registrar

S J G SEMPLE, MD, FRCP, professor of medicine

N MCI JOHNSON, MD, MRCP, senior lecturer

Department of Genitourinary Medicine, Middlesex Hospital, London W1N 8AA

S TOVEY, MRG?, seniur reg'strar

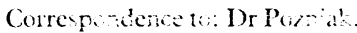

deteriorate or fail to respond should undergo bronchoscopy with bronchoalveolar lavage and transbronchial biopsy.

\section{Introduction}

It has been suggested that all patients with suspected pneumonia related to the acquired immune deficiency syndrome (AIDS) should be diagnosed with fibreoptic bronchoscopy and bronchoalveolar lavage with or without transbronchial biopsy before treatment..$^{1-3}$ We describe the clinical features, treatment, and outcome in 12 patients managed in this way and 13 subsequent patients treated empirically without initial bronchoscopy.

\section{Patients and methods}

All patients suspected of having AIDS related pneumonia fulfilled the following criteria: $(a)$ they were homosexuals and therefore in a high risk group for acquiring AIDS; $(b)$ they possessed antibody to human immunodeficiency virus (HIV); $(c)$ they had symptoms of lower respiratory tract infection; $(d)$ they had abnormal chest radiographs; and $(e)$ they had resting hypoxaemia in air or an alveolar-arterial oxygen gradient $\geqslant 20 \mathrm{~mm} \mathrm{Hg}$.

The first 12 patients (the bronchoscopy group) underwent fibreoptic bronchoscopy and bronchoalveolar lavage with or without transbronchial biopsy at or soon after presentation. Bronchoalveolar lavage fluid and histological, touch smear, and ground tissue samples from transbronchial biopsy were examined. If no diagnosis could be made further invasive investigations such as fine needle aspiration lung biopsy were performed.

In agreement with other studies we found that patients with Pneumocystis carinii pneumonia had a prolonged history of symptoms, including a dry cough and hypoxaemia, and bilateral alveolar or interstitial shadowing in their chest radiographs. ${ }^{+5}$ We also found that patients with $P$ carinii pieumonia complained of a feeling of being unable to take a deep breath and of discimfurt in the chest when they tried to do so. Pneumonias caused by bacteria have more acute histories and focal radiolegical changes and do not usually cause diffuse pulnonary infiltrates in AIDS." We therefore diagnused the subsequent 13 patients (the clinical group) on clinical criteria 
after routine sputum and blood investigations had been performed. Those suspected of having $P$ carinii pneumonia from the clinical features listed above were given high doses of intravenous co-trimoxazole (trimethoprim 20 $\mathrm{mg} / \mathrm{kg} / \mathrm{day}$, sulphamethoxazole $100 \mathrm{mg} / \mathrm{kg} /$ day in divided doses). If there was no clinical improvement after five days of treatment, or deterioration at any stage, fibreoptic bronchoscopy and bronchoalveolar lavage with or without transbronchial biopsy were performed. Patients suspected of having other pneumonias underwent fibreoptic bronchoscopy and bronchoalveolar lavage with or without transbronchial biopsy if routine sputum, blood, and serological investigations yielded no diagnosis (fig 1). We also examined sputum, induced by nebulising $4 \mathrm{ml} 2 \cdot 7 \%$ saline via a facemask, for pathogens including $P$ carinii and measured pneumocystis antigen and antibody in serum from our later patients.

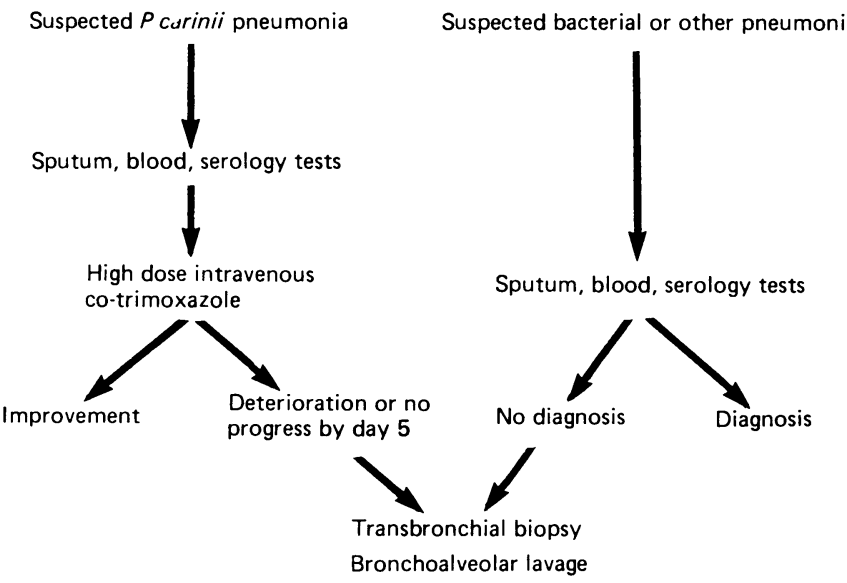

FIG 1-Plan of clinical management.

\section{Results}

Clinical features and investigations-The table shows the clinical features of the two groups of patients. Two patients in each group had Kaposi's sarcoma. More patients in the clinical group (seven patients) were known to have AIDS or to have suffered from previous pneumonic episodes than in the bronchoscopy group (three patients). Six of the 11 patients with clinically suspected $P$ carinii pneumonia had no respiratory crackles at presentation. All patients with $P$ carinii pneumonia in the bronchoscopy group had bilateral diffuse alveolar or interstitial shadowing in chest radiographs. Nine of 11 patients with suspected $P$ carinii pneumonia in the clinical group also had bilateral diffuse shadowing. The other two had normal chest radiographs initially but developed diffuse shadowing after a short period of observation. In contrast, none of the patients with bacterial pneumonias had diffuse shadowing. All had focal abnormalities; these were bilateral in one patient in the bronchoscopy group.

Diagnosis in the bronchoscopy group-Figure 2 shows that eight of the 12 patients were found to have $P$ carinii pneumonia, six by transbronchial biopsy alone, one by bronchoalveolar lavage alone, and one by fine needle aspiration biopsy after bronchoalveolar lavage and transbronchial biopsy had yielded negative results. In three of the remaining four patients bacteria (Pneumococcus in two and Pseudomonas aeruginosa in one) were isolated from both bronchoalveolar lavage and transbronchial biopsy specimens and were therefore thought to be pathogenic. Oropharyngeal organisms subsequently

Clinical features of patients in study. (Figures in parentheses are ranges)

\begin{tabular}{|c|c|c|c|c|}
\hline & \multicolumn{2}{|c|}{ Diagnosed by bronchoscopy ${ }^{\star}$} & \multicolumn{2}{|c|}{ Diagnosed clinically } \\
\hline & $\begin{array}{l}\text { Definite } P \\
\text { carinii } \\
\text { pneumonia }\end{array}$ & $\begin{array}{l}\text { Definite } \\
\text { bacterial } \\
\text { pneumonia }\end{array}$ & $\begin{array}{l}\text { Suspected } P \\
\quad \text { carinii } \\
\text { pneumonia }\end{array}$ & $\begin{array}{c}\text { Suspected } \\
\text { bacterial } \\
\text { pneumonia }\end{array}$ \\
\hline Total & 8 & 3 & 11 & 2 \\
\hline Median age (years) & $38(25-43)$ & $36(33-38)$ & $40(25-50)$ & $42(38-46)$ \\
\hline Duration of symptoms (weeks) & 2 & 0.5 & 4 & 1 \\
\hline \multicolumn{5}{|l|}{ Radiology: } \\
\hline Focal & 0 & 3 & 0 & 2 \\
\hline Diffuse & 8 & 0 & 11 & 0 \\
\hline \multirow{2}{*}{$\begin{array}{l}\text { Median } \mathrm{PaO}_{2}(\mathrm{~mm} \mathrm{Hg}) \\
\text { Median alveolar-arterial } \\
\text { gradient }(\mathrm{mm} \mathrm{Hg})\end{array}$} & $67(45-73)$ & $69(64-74)$ & $63(33-85)$ & $73(59-88)$ \\
\hline & $50(33-70)$ & $44(39.49)$ & $43(23-57)$ & $39 \cdot 5(25-54)$ \\
\hline
\end{tabular}

^One patient excluded because no firm diagnosis made. isolated by bronchoalveolar lavage alone were deemed to be contaminants. In the one remaining patient (our first) no firm diagnosis was made. Despite broad spectrum antibiotic cover, including antipneumocystis treatment, he died in the intensive care unit.

Diagnosis in the clinical group-Figure 3 shows that probable $P$ carinii pneumonia was diagnosed clinically in 11 of the 13 patients and that they were treated with high doses of co-trimoxazole. Eight improved, and two of the three who failed to respond to co-trimoxazole underwent fibreoptic bronchoscopy. $P$ carinii pneumonia was confirmed in one, who then responded to further co-trimoxazole. The other had negative results from fibreoptic bronchoscopy, bronchoalveolar lavage, and transbronchial biopsy and died from respiratory failure; needle necropsy of the lung failed to yield a diagnosis. The third patient was moribund on admission and did not undergo fibreoptic bronchoscopy; needle necropsy confirmed the clinical diagnosis of $P$ carinii pneumonia. Two of the 13 patients had suspected bacterial or other pneumonia. Haemophilus influenzae was isolated from the sputum of one, who improved with appropriate treatment. In the other all initial investigations yielded negative results, but Mycobacterium tuberculosis was isolated by both bronchoalveolar lavage and transbronchial biopsy.

Treatment-All 19 patients with proved or suspected $P$ carinii pneumonia were treated with high doses of co-trimoxazole. Side effects were similar in number and type in both groups and included a rash (three patients), thrombocytopenia (four), and nausea and vomiting (three). The drug was stopped in five patients. Pentamidine was given to seven of the 19 patients (six intramuscularly and one intravenously). Five were changed to pentamidine from co-trimoxazole and two were given both drugs concurrently. A decrease in renal function occurred in five patients; in one treatment had to be stopped.

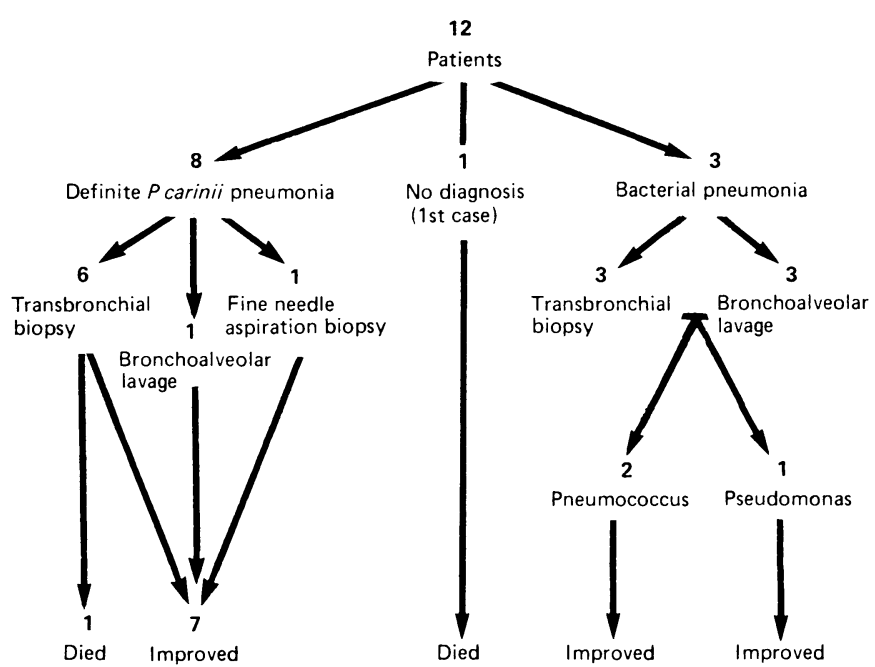

FIG 2-Diagnosis and outcome in patients diagnosed by bronchoscopy.

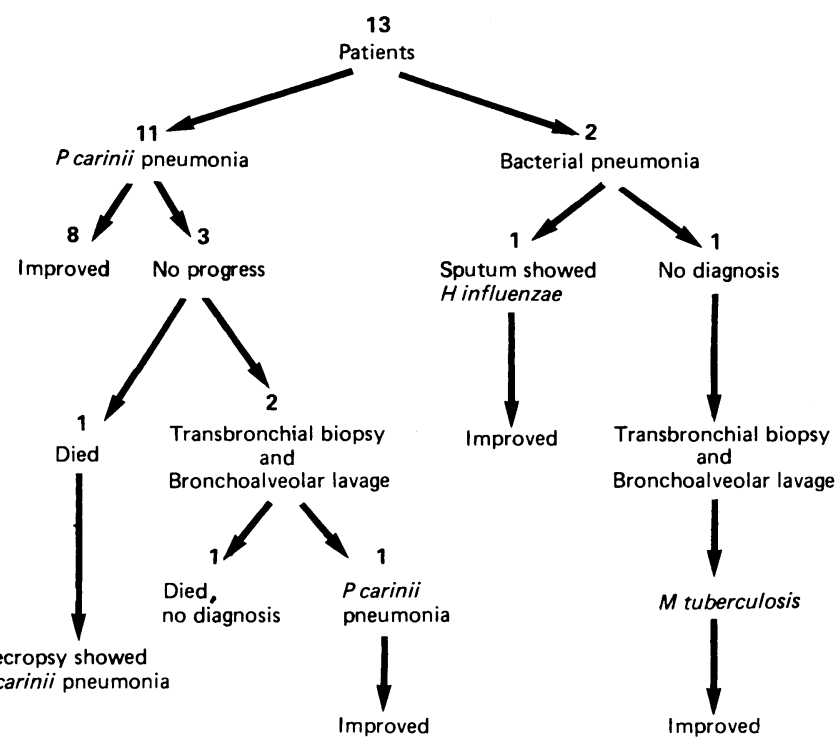

FIG 3-Diagnosis and outcome in patients diagnosed clinically. 
Survival-Early survival-that is, eight weeks from diagnosis of $P$ carinii pneumonia-was six out of eight patients in the bronchoscopy group and nine out of 11 in the clinical group. Only one patient with $P$ carinii pneumonia in the bronchoscopy group was still alive at 40 weeks. In the clinical group seven patients survived for 16 to 40 weeks.

\section{Discussion}

Transbronchial biopsy is currently important in the diagnosis of $P$ carinii pneumonia, being capable of diagnosing up to $93 \%$ of cases when used alone and even more when combined with other procedures such as bronchoalveolar lavage, touch imprints, and bronchial brushings. ${ }^{3}$ A recent study that emphasised the importance of close liaison with a specifically skilled cytopathology department suggested that bronchoalveolar lavage alone may be diagnostic in $98 \%$ of cases $^{7}$; this contrasts with figures of $79 \%$ to $85 \%$ in earlier studies. ${ }^{23}$ In the bronchoscopy group we found that transbronchial biopsy had a higher diagnostic rate than bronchoalveolar lavage. We did not obtain bronchial brushings routinely.

Our decision to treat 13 patients with suspected AIDS related pneumonia on clinical grounds alone and to perform fibreoptic bronchoscopy, bronchoalveolar lavage, and transbronchial biopsy only in those who failed to respond or who deteriorated arose from many considerations.

Firstly, large studies in the United States have shown that $66 \%$ to $85 \%$ of all AIDS pneumonia is due to $P$ carinii pneumonia. ${ }^{1.3}$ In those patients whose symptoms suggested $P$ carinii pneumonia we therefore questioned whether an invasive procedure that is not without definite risk to the patient ${ }^{8}$ and theoretical risk to the operator was justified.

Secondly, the potential number of patients with AIDS and pulmonary complications is increasing. In 1988 alone there may be 2500 patients with AIDS in the United Kingdom, of whom 750 may have $P$ carinii pneumonia" (Communicable Disease Surveillance Centre). Bronchoscopy for every case may be unrealistic.

Thirdly, immediate treatment on clinical diagnosis avoids any delay incurred by waiting for fibreoptic bronchoscopy and the results of bronchoalveolar lavage with or without transbronchial biopsy. Interestingly, any subsequent isolation of $P$ carinii does not seem to be affected by the duration of treatment with cotrimoxazole. ${ }^{3+10}$

Fourthly, staff anxiety about possible infection with HIV was high. Despite reassuring results of studies of nosocomial and needlestick exposure ${ }^{11-13}$ at least one case of seroconversion has been reported in the United Kingdom. ${ }^{14}$

Fifthly, non-lifesaving surgery and postmortem procedures in patients who are HIV positive have been curtailed or are unavailable. ${ }^{15}$ Patients who gave negative results on bronchoscopy were therefore no further forward with regard to diagnosis.

Lastly, bronchoscope availability has been limited. The Middlesex bronchoscope reserved for patients with AIDS was often on loan to other units and required lengthy sterilisation with ethylene oxide. More recent models of fully immersible bronchoscopes may make sterilisation procedures shorter.

Certain theoretical problems arise from our suggested management. Atypical presentations of $P$ carinii pneumonia occur-for example, as focal shadows in chest radiographs. ${ }^{16}$ In our approach such patients would undergo fibreoptic bronchoscopy if no diagnosis could be made after routine investigations. Other infections may also present as $P$ carinii pneumonia, and failure to respond to co-trimoxazole, or clinical deterioration, would warrant fibreoptic bronchoscopy. Prior treatment with co-trimoxazole should not affect isolation of mycobacteria, fungi, or viruses, though it would treat many bacterial pneumonias, including that caused by Streptococcus pneumoniae. In this case blood culture, countercurrent immune electrophoresis of serum and urine, and examination of induced sputum might be diagnostic.

Multiple organisms may coexist with $P$ carinii in a pneumonic illness. ${ }^{316}$ Our approach is aimed at diagnosing and treating $P$ carinii pneumonia. Other organisms would often be discovered by the usual means or in those who failed to improve. It should be remembered that many organisms associated with AIDS-for instance, cytomegalovirus-cause pneumonia that may be difficult to diagnose ${ }^{16}$ and either cause high mortality despite treatment ${ }^{6}$ or are treated with experimental drugs. ${ }^{17}$

Starting treatment with high doses of relatively toxic drugs without a bacteriological diagnosis may be contentious. This, however, is accepted clinical practice in the treatment of severe pneumonias or suspected atypical pneumonias. In our study the clinical diagnosis of $P$ carinii pneumonia in most cases (eight of 11) was supported by subsequent response to intravenous cotrimoxazole or pentamidine. In another two of the 11 patients the clinical diagnosis was confirmed by subsequent histological findings.

One argument for routine fibreoptic bronchoscopy is to confirm a diagnosis of AIDS. The identification of Str pneumoniae or $M$ tuberculosis by fibreoptic bronchoscopy, however, does not at present fulfil the criteria of the Center for Disease Control for the diagnosis of AIDS, though these pneumonias occur far more commonly in patients with AIDS. ${ }^{318}$ Counselling patients with high risk factors for AIDS who show evidence of HIV infection and $P$ carinii pneumonia has not been problematic in our experience.

Other non-invasive investigations may be of use in diagnosis. The role of pneumocystis serology in pneumonia related to AIDS is being evaluated. Induced sputum examination for pneumocystis has been useful in two recent studies. ${ }^{19} 20$

Despite the problems discussed our results suggest that a clinical approach to suspected pneumonia related to AIDS may be useful. We conclude that, in high risk patients with appropriate clinical features of $P$ carinii pneumonia, starting treatment with high doses of co-trimoxazole is justified. Bronchoscopy should be performed on those who fail to respond. Focal radiological disease is unlikely to be $P$ carinii pneumonia and should be investigated by early bronchoscopy if initial non-invasive investigations are unhelpful.

We thank Margot Tomlinson for help with the manuscript.

\section{References}

1 Coleman DL, Dodek PM, Luce JM, Golden JA, Gold WM, Murray JF. Diagnostic utility of fiberoptic bronchoscopy in patients with Pneumocystis carinii pneumonia and the acquired immune deficiency syndrome. Am Rev Respir Dis 1983;128:795-9.

2 Stover DE, White DA, Romano PA, Gellene RA. Diagnosis of pulmonary disease in acquired immune deficiency syndrome: role of bronchoscopy and bronchoalveolar lavage. Am Rev Respir Dis 1984;130:659-62.

3 Murray JF, Felton CP, Garay SM, et al. Pulmonary complications of the acquired immunodeficiency sundrome. $N$ Engl f Med 1984;310:1682-8.

4 Engelberg LA, Lerner CW, Tapper ML. Clinical features of pneumocystis pneumonia in the acquired immune deficiency syndrome. Am Rev Respir Dis 1984;130:689-94.

5 Swinburn CR, Pozniak AL, Sutherland S, Banks R, Teal A, Johnson NMcI. Early experience and difficulties with bronchoalveolar lavage and transbronchial biopsy in the diagnosis of AIDSassociated pneumonia in Britain. Thorax 1985;40:166-70.

6 Stover DE, White DA, Romano PA, Gellene RA, Robeson WA. Spectrum of pulmonary diseases associated with the acquired immune deficiency syndrome. Am f Med 1985;78:429-37.

7 Ornstein $M$, Webber CA, Cash M, Heurich AE. Value of bronchoalveolar lavage in the diagnosis of pulmonary infection in acquired immune deficiency syndrome. Thorax 1986;41:345-9.

8 Feldman NT. An assessment of transbronchial lung biopsy. N Engl f Med 1975:293:299.

9 McEvoy $M$, Tillett HE. Some problems in the prediction of future numbers of cases of the acquired immunodeficiency syndrome in the UK Lancet 1985 ;ii:541-2.

10 Rosen MJ, Tierstein AS, Chuang MT, Brown LK. Response of therapy of Pneumocystis carinii pneumonia in patients with acquired immune deficiency syndrome. Chest 1983;84:347.

11 Hirsch MS, Wormser GP, Schooley RT, et al. Risk of nosocomial infection with human T-cell lymphotropic virus HI (HTLV-III). N Engl f Med 1985;312:1-4.

12 Wormser GP, Joline C, Duncanson F, Cunningham-Rundles $S$. Needlestick injuries during the care of patients with AIDS. $N$ Engl 7 Med 1984;310:1461.

13 Sande MA. Transmission of AIDS. The case against casual contagion. $N$ Engl $\mathfrak{f}$ Med 1986;314:380-2.

14 Anonymous. Needlestick transmission of HTLV-III from a patient infected in Africa [Editorial]. Lancet 1984;ii:1376-7.

15 Advisory Committee on Dangerous Pathogens. Acquired immune deficiency syndrome (AIDS) interim guidelines. London: Department of Health and Social Security, 1984:16.

16 Marchevsky A, Rosen MJ, Chrystal G, Kleinerman J. Pulmonary complications of the acquired immunodeficiency syndrome. A clinicopathologic study of 70 cases. Hum Pathol 1985;16: immunodefic

17 Furio MM, Wordell CJ. Treatment of infectious complications of acquired immunodeficiency syndrome. Clinical Pharmacology 1985;4:539-52.

18 Polsky B, Gold JWM, Whimbey E, et al. Bacterial pneumonia in patients with the acquired immunodeficiency syndrome. Ann Intern Med 1986;104:38-41.

19 Pitchenik AE, Ganjei P, Torres A, Evans DA, Rubin E, Baier H. Sputum examination for the diagnosis of Pneumocystis carinii pneumonia in the acquired immunodeficiency syndrome. Am Rev Respir Dis 1986;133:226-9.

20 Bigby TD, Margolskee D, Curtis JL, et al. The usefulness of induced sputum in the diagnosis of Pneumocystis carinii pneumonia in patients with the acquired immunodeficiency syndrome. Am Rev Respir Dis 1986;133:515-8.

(Accepted 3 fulv 1986) 